\title{
Assessing the Effectiveness of Public Investments in Cultural Built Heritage: The Case of the Umbertine Forts System in Italy
}

\author{
Giuseppina Cassalia $^{1(\bowtie)}(\mathbb{D})$, Veronica Calvieri ${ }^{2}$, Immacolata Lorè ${ }^{1}$, \\ and Francesco Calabrò ${ }^{1}$ \\ ${ }^{1}$ Mediterranea University of Reggio Calabria, 89100 Reggio Calabria, Italy \\ giuseppina.cassalia@unirc.it \\ ${ }^{2}$ Club UNESCO, Campo Calabro, Italy
}

\begin{abstract}
The paper deals with the topic of the allocation of resources and investment strategies in cultural built heritage. The valorization of cultural assets is often guaranteed by the intervention of public funding. The need to allocate these funds efficiently and effectively, together with the transparency duties to which public administrations are subject, necessitates a careful measurement of the economic, cultural, environmental and social effects. Accordingly, the paper outlines the starting framework of a study on the ex-post evaluation of the effectiveness of public intervention towards the restoration and valorization of three forts in the Umbertine Forts System, located in the Metropolitan City of Reggio Calabria, southern Italy.

The open remarks raised by the preliminary step of the study evoke questions both about the topic of evaluation tools and the methods used in the ex-post evaluation of the effectiveness of public intervention towards cultural built heritage restoration and valorization, and also on the topic of local governance, strategic planning and management of cultural heritage.
\end{abstract}

Keywords: Public investments $\cdot$ Cultural built heritage $\cdot$ Ex-post evaluation tools $\cdot$ Umbertine Forts System $\cdot$ Cost benefits analysis

\section{Introduction}

The enhancement of cultural heritage oriented towards segments of new demand and with increasingly sustainable use methods represents a fundamental pillar of the European strategy in favor of intelligent growth. In particular, culture has always played a primary role within the Italian economic system as an engine for the country's growth. In terms of policies, the interest in cultural activities is due both to the employment potential closely connected to the sector, and to the multiple

The paper is the result of the joint work of the authors. Although scientific responsibility is equally attributable, the abstract and Sects. 2, 2.1, 3, 3.2 and 4 were written by G. Cassalia while Sects. 1 was written by F. Calabrò, 2.2 by V. Calveri and 3.2 by I. Lorè.

(C) The Author(s) 2020

C. Bevilacqua et al. (Eds.): NMP 2020, SIST 177, pp. 197-210, 2020.

https://doi.org/10.1007/978-3-030-52869-0_17 
interrelationships that bind it to other economic spheres, the agri-food, tourism, crafts, research activities and development.

This leads to the concept of shared value "which focuses on the connections between societal and economic progress" [1].

Furthermore, numerous European documents stress the potential of cultural heritage as an engine of growth in terms of: new and higher quality job opportunities, able to exploit and spread the use of new information technologies; b) redevelopment factors of urban environments and the driving force of development of rural areas and minor centers of architectural and landscape value; and c) drivers for social cohesion because the enhancement of local goods and traditions increases the awareness of the collective heritage and enables the strengthening of the sense of belonging in the communities [2, 3].

The valorization of cultural assets, notoriously characterized by poor profitability, is often guaranteed by the intervention of a public body or a third party interested in knowing how and with what effects the resources provided have been used. The need to allocate these funds efficiently and optimally, together with the transparency duties to which public administrations are subject, necessitates careful measurement of the effects of an economic investment $[4,5]$. In this regard, the measurement of impact is becoming more and more relevant in investments with social spill overs, but, at the same time, it is really complex because of the lack of track record and historical data. In the literature and practice, as demonstrated in the following chapter, many instruments have been developed for the measurement of the impact of cultural projects. Almost all the tools are based on two-dimensional analysis: economic-financial performance and social and/or environmental impact. Because of the peculiarities and constraints of the cultural heritage sector, further steps should be taken in the development of methodologies suitable for the addressed field. A holistic approach should be chosen also for these methodologies and instruments to measure the spillover effects from cross-cutting issues regarding trans-categories, as well as trans-sectors, benefits [6].

The paper outlines the starting framework of a study on the ex-post evaluation of the effectiveness of public intervention toward the restoration and valorization of three forts of the Umbertine Forts System, in the Metropolitan City of Reggio Calabria, southern Italy. Regions like Calabria have been the target during the last three European programming cycles of substantial public investments, but interventions have not yet produced significant socioeconomic effects. Funding pressures reinforce the need for a better understanding of how local governments can invest in the mitigation of territorial disparities and what the communities get in return. The open questions raised by the preliminary step of the study presented here emphasize how the culture of evaluation is an essential step towards achieving the overriding key objectives of efficiency, transparency, and accountability, with the aim of determining both the costs and the benefits of publicly financed projects, and to improve the efficiency and effectiveness of that investment. 


\section{Cultural Built Heritage Public Investments in Times of Scarce Resources: Burdensome Encumbrance or Development Engine?}

The allocation of resources and investment strategies are crucial issues for the cultural sector. In recent decades, the idea of cultural built heritage as a weight bearing on the public sector has evolved into the concept of a strategic asset capable of increasing the attractiveness and competitiveness of some territories [2].

This important evolution in theoretical terms encounters, however, a strong limit from the increasingly strict constraints placed on public spending, which have constituted a real, generalized collapse of investments. Although the need to attract private resources and skills to the sector and to enhance the synergies between cultural heritage and tourist accommodation has long been highlighted, it is clear that the role of public investment remains crucial [7].

Moreover, given the low absorption rate of EU Structural Funds, the debate in Italy continues about the extent to which, after decades of subsidies, the European Regional Policy is effective. This explains the attention to the programming strategies of these resources and to the selection of the territories and themes to invest in, so as to arrive at the methodologies for measuring the impacts actually obtained [8].

Far from finding an answer to the question, the study aims at contributing to the debate on the effectiveness of public investments in cultural projects and to identifying the roles and responsibilities of the multi-level authorities, by choosing the Umbertine Forts System of the City of Reggio Calabria (Italy) as an applicative case. As a preliminary step of the study, this contribution adopts an analytical and interpretive approach that could be easily exported to other public planning processes, to support local policy makers in defining systemic territorial strategies.

\subsection{Cultural Sector Potentiality and Investment Strategies in Calabria}

Considering the strategic role of culture and the scarcity of financial resources available to the Calabria Region (Italy), it is essential to develop and disseminate a culture of measurement in the cultural field that allows evaluating ex ante and in itinere, during the planning phase so as to allocate resources more effectively and to appraise ex post the cultural heritage investment effects on the territory. It is the authors' opinion that the developmental potential related to cultural heritage depends on the endowment of resources, but also on the effectiveness of the enhancement strategies [9, 10].

Regarding the first aspect, in 2014 Calabria was assessed to be among the regions with the most advantageous capital and cultural heritage assets in Italy ${ }^{1}$. Likewise, from a tourism point of view, there was notable improvement based on the seasonal

\footnotetext{
1 "Big Data e Social Network per Istruzione e Cultura in Calabria", presented the $16^{\text {th }}$ of October 2014 in Rome, Palazzo dell'Informazione, Sala Mastai.
} 
adjustment of flows: the attendance indicator (days per inhabitant) in non-summer months in 1998 improved from 0.39 (Italy, 1.98) to 0.92 (Italy, 2.90) in $2018^{2}$.

However, from a socioeconomic perspective, the Calabria region is characterized by a persistent gap both in relation to the national framework and the other Southern regions. Calabria, and the city of Reggio Calabria in particular, still lags behind the main employment objectives set by the European Councils of Lisbon and Gothenburg and possesses a structural condition that impedes the regional economy and creates a competitive gap concerning the main factors underlying territorial development [8]. This situation spans the gamut-from innovation, which is still substantially lacking in material (financial and human) means (\% companies who have introduced technological innovations 23.2 (Italy, 35.7) in 2016), up to globalization and the difficulties related to access to foreign markets (export capacity 1.3 (Italy, 24.7) in 2016). Small and microenterprises are struggling, and the craft sector, the fundamental production sector, suffers from a thinning phenomenon. Building and agriculture are still, judging from the available data, in recession. The regional social framework reflects the difficult state of the labor market, indicating a level of social capital eroded by decades of migration. The phenomenon of emigration, especially of young people from Calabria, to the north of the country is structural, and immigration from outside the European Community does not compensate for the flow of Calabrian departing to other regions of Italy (Total growth rate -4.3 (Italy, -1.7 ) in 2017$)^{3}$. In these conditions, the comparison with the other regions of the European Union is not favorable.

In terms of investments, the last two programming cycle have provided financing of 1,146 "culture and tourism" projects in Calabria, with about 500 million $€$ of public cost, $248 €$ per capita financing and 377 million $€$ of expenditures ${ }^{4}$. In this context, the three most recent "culture and tourism" projects related to the Forts System of the Metropolitan City of Reggio Calabria have been selected as focus of next year's research studies.

The topic is introduced in the next section and the development of the preliminary research framework has proceeded through the following steps: (1) research question identification and context definition; (2) investments evaluation methods and tools in the field of cultural heritage; (3) illustrative cases of impact analysis studies; and (4) concluding remarks. After a descriptive analysis of the methodologies internationally used to verify the effectiveness of investments in the cultural heritage field, three example cases are identified to highlight the positive and negative aspects of the most frequent evaluation tools used. In conclusion, this preliminary study offers a contribution to the efficiency assessment, highlighting the need for an economic evaluation approach to support local authorities in addressing the challenge of fostering cultural assets as an engine for local sustainable development.

\footnotetext{
${ }^{2}$ Data for the study have been gathered via the "OpenCoesione" database, Italy's national web portal on the implementation of investments planned in the 2007-2013 and 2014-20 programming periods by Regions and National Administrations via cohesion-policy resources.

${ }^{3}$ Report Regione Calabria, Dati e informazioni sullo stato e sull'evoluzione del profilo socioeconomico del terriorio, 2019. S.I.S.PR.IN.T Project, Unioncamere: http://www.uc-cal.camcom.gov. it/, last accessed 2020/01/29.

${ }^{4}$ https://opencoesione.gov.it/en/territori/calabria-regione/, last accessed 2020/01/29.
} 


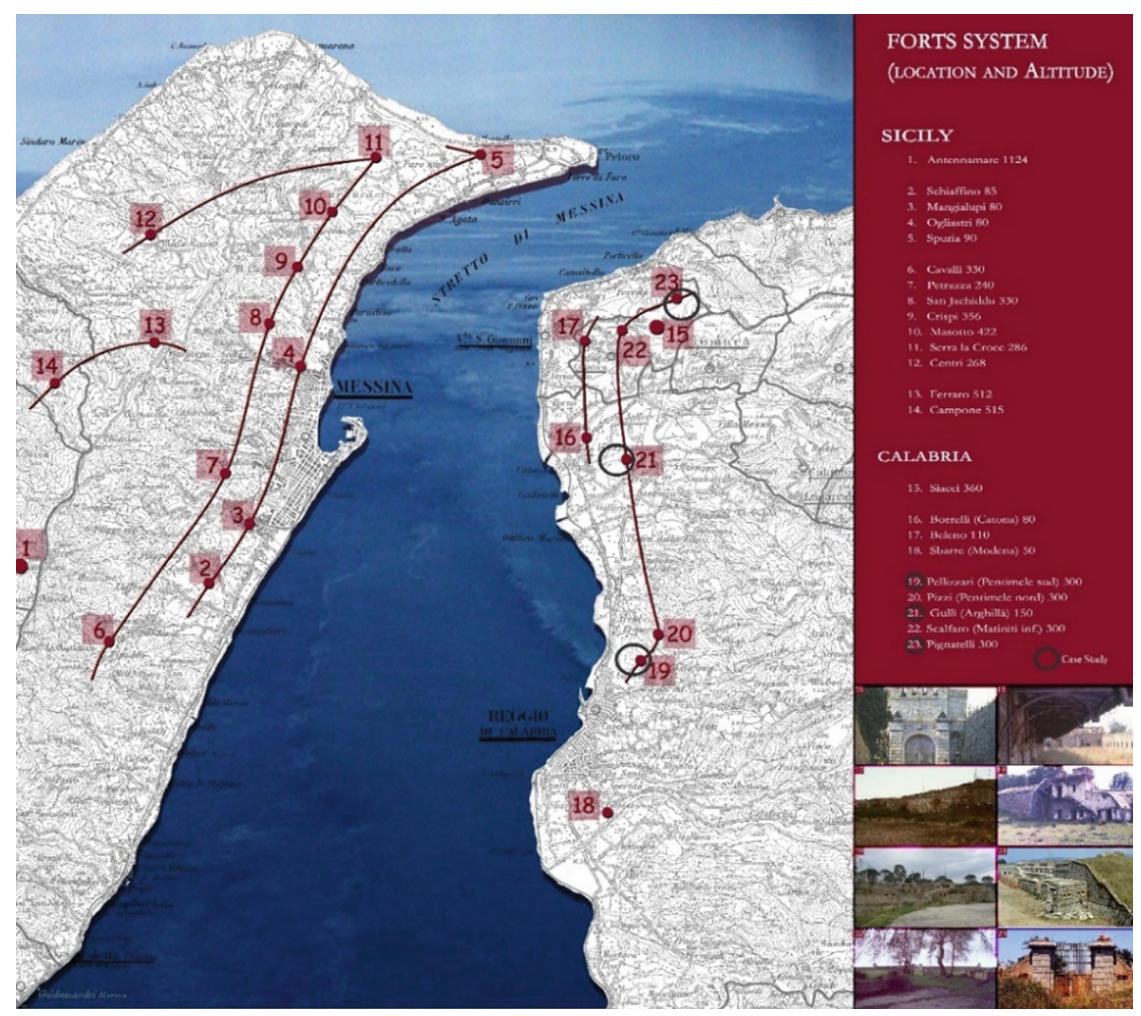

Fig. 1 Map of the Umbertine Forts System. Strait of Messina. (Source: author's adaptation of the exhibition leaflet "I fortini di Pentimele nel sistema della fortificazioni nell'area dello Stretto", co-edited by Alessandro Rugolo)

\subsection{An Applicative Case: The Umbertine Forts System}

The paper presents a preliminary framework of the study on the appraisal of the effectiveness of public investments towards the valorization of cultural built heritage. As a case study, the system of the Umbertine Forts located along the Strait of Messina, Italy. The so-called Umbertine Forts System was built between 1882 and 1892, after the unification of Italy, to support the expansionism of King Umberto I and to defend the Strait of Messina, which was considered an important strategic point in the Mediterranean zone and an important passageway to the north [11]. The defensive system of the Strait of Messina consisted in 22 forts, called batteries. Thirteen were built on the Sicilian coast and nine on the Calabrian coast. The forts system, unique of its kind for longitudinal development along a whole coastline and for the characteristics of its architectures, belong to the typology of the established field. The sites selected as the locations for the Sicilian and Calabrian constructions were intended to guarantee a field of view so that the principal fortifications, situated on the highest ground, dominated those below and, at the same time, protected the entire arm of the sea by the emplaced artilleries' field of fire (see Fig. 1). 
The peculiarity of this cultural built heritage lies in its essence of being a serial asset that is configured as a unitary whole, even if articulated and complex in nature, both from a geographical/landscape point of view and from an architectural/built one. The study, at this stage, focuses on the Calabrian side of the fortress system and, in particular, on those subject to restoration interventions. In Fig. 1, these are identified as n. 23 the Poggio Pignatelli Fort, n. 21 the Fort in Arghillà and n. 19 the Fort in Pentimele.

The very first question arising from the study deals with the governance approach to the conservation and management of this cultural built heritage. Aware of the specific and unique cultural landscape evidenced by the Sicilian and Calabrian fortress system, why was it conceived as a sum of single buildings? In this first step of the study, no plans nor documents have been found regarding a strategic vision for the conservation and management of the forts as a system. As will be showed, more than 10 million euros of public funding have been spent for the conservation and valorization of three of these forts on the Calabrian side of the system. And, according to the first results, two out of the three are not in operation.

A brief description of the three forts and the infrastructure investments in question follows to outline the framework for further considerations concerning the allocation of resources and investment strategies.

The Fort in Arghillà. The Gullì battery, today known as Ecolandia, is located in Arghillà, a north suburb of Reggio Calabria. It was restored in the late 1990s, through the European URBAN I program, during the 1994-99 programming period (Table 1). In particular, the work involved the restoration of the fort, the construction of an amphitheater of about 800 seats and the renewal and valorization of equipped green spaces from 1998 to 2001. The fort has long remained unused and, since 2011, has been managed by a group of companies that have turned it into an Environmental Technology Playground Park. Due to the fact that the 1994-99 programming period was not well monitored, there are no public data on the timing and detailed public spending of the intervention. Accordingly, this part of the study needs to be further developed. Nevertheless, it's known that seven million euros have been invested and about six million and five hundred thousand euros officially disbursed (Table 2).

The Forts in Pentimele. These forts rise on the hill of Pentimele and are sit in a panoramic position over the city of Reggio Calabria. Due to the state of neglect, the area, despite being very close to the city, is not densely populated and does not host any type of accommodation (except from a bed \& breakfast). The structural and architectural restoration of the Umbertino Fort was part of the 46 new restoration interventions in the regions of the Convergence Objective, 2007-2013 programming period. The planned interventions in the Calabrian territory were 14, and among them were the enhancement of the Pentimele Fort. It obtained an investment of three million euros, divided as follows: $10 \%$ EU fund, 3\% Revolving Fund (national co-financing) and 87\% Revolving Fund (Cohesion Action Plan). The work began in April 2016 and was completed in February 2017. An analysis of the data provided by OpenCoesione shows that the total expenditure at the end of the work was $71 \%$ of the programmed financing. While the inauguration of the fort took place in June 2017, nevertheless, the structure is not in operation to date. 
Table 1. Framework of the public intervention on the forts (1)

\begin{tabular}{l|l|l|l|l|l}
\hline Fort name & Municipality & Intervention & $\begin{array}{l}\text { Programming } \\
\text { period }\end{array}$ & EU fund & Program \\
\hline $\begin{array}{l}\text { Fort in } \\
\text { Arghilla, }\end{array}$ & $\begin{array}{l}\text { Reggio } \\
\text { Calabria }\end{array}$ & $\begin{array}{l}\text { Restoration } \\
\text { and } \\
\text { Valorization }\end{array}$ & $\begin{array}{l}\text { P.P. 1994- } \\
1999\end{array}$ & $\begin{array}{l}\text { STRUCT. } \\
\text { FUND* }\end{array}$ & $\begin{array}{l}\text { Urban I Community } \\
\text { Initiative }\end{array}$ \\
\hline $\begin{array}{l}\text { Fort in } \\
\text { Pentimele }\end{array}$ & $\begin{array}{l}\text { Reggio } \\
\text { Calabria }\end{array}$ & $\begin{array}{l}\text { Restoration } \\
\text { and } \\
\text { Valorization }\end{array}$ & $\begin{array}{l}\text { P.P. 2007- } \\
2013\end{array}$ & ERDF** & $\begin{array}{l}\text { IROP Cult. and Tourism } \\
\text { CAP Cultural } \\
\text { Heritage**** }\end{array}$ \\
\hline $\begin{array}{l}\text { Poggio } \\
\text { Pignatelli } \\
\text { Fort }\end{array}$ & $\begin{array}{l}\text { Campo } \\
\text { Calabro }\end{array}$ & $\begin{array}{l}\text { Restoration } \\
\text { and } \\
\text { Valorization }\end{array}$ & $\begin{array}{l}\text { P.P. 2007- } \\
2013\end{array}$ & ERDF & ROP Calabria***** \\
\cline { 2 - 6 } & $\begin{array}{l}\text { System } \\
\text { Valorization }\end{array}$ & $\begin{array}{l}\text { P.P. 2014- } \\
\text { 2020 }\end{array}$ & DCF*** & Reggio Calabria Pact \\
\hline
\end{tabular}

*Structural Fund; ** European Regional Development Fund; ***Development Cohesion Fund; **** Integrated Regional Operational Program Cult. and Tourism - Cohesion Action Plan Cultural Heritage; *****Regional Operational Program

Table 2. Framework of the Public Intervention on the Forts (2)

\begin{tabular}{l|l|l|l|l|l|l}
\hline Fort's name & $\begin{array}{l}\text { Progr. } \\
\text { period }\end{array}$ & $\begin{array}{l}\text { Financial } \\
\text { status }\end{array}$ & $\begin{array}{l}\text { Project } \\
\text { status }\end{array}$ & $\begin{array}{l}\text { Procedural } \\
\text { status }\end{array}$ & $\begin{array}{l}\text { Tot. pub. } \\
\text { investment }\end{array}$ & Tot. payment \\
\hline $\begin{array}{l}\text { Fort in } \\
\text { Arghilla' }\end{array}$ & $\begin{array}{l}\text { P.P. 1994- } \\
1999\end{array}$ & Cleared & Completed & Executed & $7,000,000.00 €^{*}$ & $6,500,000.00 €^{*}$ \\
\hline $\begin{array}{l}\text { Fort in } \\
\text { Pentimele }\end{array}$ & $\begin{array}{l}\text { P.P. 2007- } \\
2013\end{array}$ & In progress & In progress & $\begin{array}{l}\text { Execution of } \\
\text { works }\end{array}$ & $3,000,000.00 €$ & $2,134,264.00 €$ \\
\hline $\begin{array}{l}\text { Poggio } \\
\text { Pignatelli Fort }\end{array}$ & $\begin{array}{l}\text { P.P. 2007- } \\
\text { 2013 }\end{array}$ & Cleared & Completed & Test & $750,000.00 €$ & $617,952.00 €$ \\
\cline { 2 - 6 } & $\begin{array}{l}\text { P.P. 2014- } \\
\text { 2020 }\end{array}$ & Not started & In progress & $\begin{array}{l}\text { Preliminary } \\
\text { project }\end{array}$ & $800,000.00 €$ & 0 \\
\hline
\end{tabular}

* approximate amount

The Forts in Campo Calabro. Three of the forts of the Umbertine System are situated in the territory of the Campo Calabro municipality, in the settlement of Matiniti, on the hills above the town. Manned by Italian Army troops until 1984, the forts were decommissioned as military structures and have suffered a gradual decline due to the interruption of maintenance work and vandalism. The Poggio Pignatelli fort is located one $\mathrm{km}$ from the town, and its restoration and enhancement work began in June 2014 and ended in November 2015. Approximately $€ 618,000.00$ was spent in the first instance, of which $75 \%$ came from European Union and $25 \%$ from national cofinancing. The management of the internal areas and buildings of the fort was assigned to various associations that, after an initial phase of activity, stopped operating. A second round of funding has been committed within the 2014-2020 programming period. Eight hundred thousand euros is expected to be spent by the end of 2020 with the aim of enhancing the structure of the Umbertine fort with a specific environmental approach aimed at creating a museum. 
In order to get valid results, it is essential to emphasize some aspects that will influence the methodology on the topic in the ensuing research steps. First of all, as previously stated, the restoration interventions were allocated to individual elements/buildings. This underlines a lack of planning and an absent overview of the Fortress System as a serial cultural built heritage - if not of the Strait of Messina Area, between the Sicilian and Calabrian coasts - located in the Metropolitan City of Reggio Calabria. Second, this study phase focuses only on public investments for restoration and enhancement interventions, falling under the "infrastructure" type of investment. For the record, over the years, Ecolandia, the fort in Arghillà, has received further and substantial (European, National and Regional) public funding for the implementation of cultural activities, social services and scientific activities. These funds are not counted in the study.

In summary and in a very rough way, it can be stated that around $€ 11,550,000$ have been committed for the restoration and conservation of three military fortresses, and on average $80 \%$ of the programmed funds have actually been spent.

The question that arises from this first analysis, in need of further study, deals with the impact that this public investment had and will have on the territory. How do we evaluate the effectiveness of these interventions? What are the generated outcomes on the various stakeholders such as the community, local businesses, associations, administrations and potential tourists?

To deal with this topic, the following section will illustrate a series of evaluation tools used in various cases to measure the economic values provided by cultural built heritage.

\section{Toward the Assessment of the Public Investments Effectiveness: Methodological Considerations}

The most sensitive issue in the investments analysis is that relating to the measurement of the impacts obtained: for instance, the question refers to whether and how much the financed projects have actually contributed to increasing the tourist attractiveness of the concerned areas and if the expected effects in terms of promotion of jobs and income opportunities have actually been achieved. In economic terms, there is now a large literature on the available methodologies and the limits of each, and the analytical choices are adapted to the characteristics of the individual case [12]. More in depth, the assessment and measurement of economic values provided by cultural built heritage has increasingly been recognized as an essential part of cultural policy as underlined by Lichfield (1988), Pearce and Mourato (1998) and Ost and Van Droogenbroeck (1998) [13-15]. The former framed very clearly the evaluation tools that aim to predict, estimate and value the costs and benefits and their distribution among the parties involved in and affected by cultural built heritage: financial and social financial analysis (FA, SFA); cost benefits and social cost benefits analysis (CBA and SCBA); and community impact analysis (CIA).

In accordance with the latter, the interpretation of the processes of value creation and impact generation on the territory for all the stakeholders of an investment are central elements of a comprehensive and dynamic network system based on the 
measurement of shared value [1]. It is the authors' belief that it is necessary to represent the value of a project with the awareness that its impact does not only concern the financial sphere, but should be valued in a multi-attribute microeconomic perspective, considering the economic, social, environmental and cultural domains. Moreover, it is also significant to pay attention both to the concept of assessing the impact of the infrastructure investments and to the concept of measuring the outcomes. The latter has the aim of qualifying and quantifying the added value of the project with respect to the set objectives, taking into account the way in which the implementation process took place and the changes that may have occurred in the reference context. The former considers the persistence over time and the scope of immediate results. However, both evaluations deal with external effectiveness or with the degree of satisfaction of the needs from which the project was generated.

\subsection{Tools and Methods for Evaluating Investments in Cultural Projects}

Recent studies have highlighted pros and cons of various methods, bringing to light exemplary cases and possible connections. The CHCFE report commissioned by the European Union (2015) and David Throsby's study on Investment in Urban Heritage commissioned by the World Bank (2012) are two examples [16, 17].

These studies argue that many empirical studies have used stated preference methods such as contingent (CVM) to evaluate the welfare effects of cultural heritage investments by assessing the willingness of visitors, local residents or other stakeholders to contribute toward the costs of preserving the site of interest [18]. The improvement of experimental choice methods has resulted in an expansion of interest in the use of DCM as a technique for determining demand for various different attributes of a heritage site, such as its beauty, its amenity, its entry price, etc. [19].

Other researches relate the appraisal of the impacts of a cultural heritage investment based on a quantitative analysis of a statistical data approach. This is the case of the Guggenheim Museum Bilbao studied by Plaza (2006), who estimated the impacts of the Museum on overnight stays, employment, and fiscal revenues for the city of Bilbao [20]. Moreover, hedonic price studies of heritage values focus on real estate prices for listed property to ascertain the extent to which the heritage characteristics influence the market valuation [21]. A diverse form of empirical research is that aimed at assessing the benefits of investment in cultural heritage. Some studies look at the valuation of cultural landscapes and at environmental assets defined as cultural heritage [22]. Empirical assessment of the use benefits of heritage is usually straightforward, being based on measurement of observable financial flows generated by market transactions. Revealed preference data can also be used to determine a range of use and non-use benefits through the application of travel-cost methods [23].

Finally, there is cost-benefit analysis (CBA) in which the aggregated present value of the net benefits produced by the investment project is compared to the present value of the project's capital costs [24, 25]. Moreover, there is social cost-benefit analysis that captures the benefits of an investment with large spill-over effects [26, 27].

Given the purposes of the research, three case studies of impact assessment of cultural heritage projects are reported below. The cases involve cultural immovable 
heritage in three different European areas ${ }^{5}$ : Belgium, Macedonia, and Poland. The casestudy selection was based on the following criteria: (1) cross-geographical contexts; (2) focus on built heritage; (3) assessment approaches; and (4) results obtained.

\subsection{Example Cases of Cultural Projects' Effects Evaluation}

The first case study concerns the city of Mechelen (Belgium) [16]. The main research question of this study was how to assess direct and indirect impacts of immovable heritage on the economy, society, culture and environment in the case of the chosen object of study, the historic city center of Mechelen. The aim was to estimate the heritage spillovers in the fields of economy, society, culture and environment, and the chosen approach was qualitative, rather than quantitative, and the selected method was an indicator-based examination. The study is based on secondary data sources supplemented with evidence from stakeholder consultations and on the findings of the conducted survey. The results indicate that there is a correlation between the heritage and its impact on the society, but other factors also play a significant role in this process. The research highlights the lack of available data with regard to some of the indicators.

The second case study examined the impact of cultural heritage in Macedonia conducted by Throsby [17]. He applied an ex-post CBA assessing the economic impacts of heritage investment, in the historic town center of Skopje. This report proposed a procedure for conducting an ex-post economic impact analysis and quantified a series of indicators and other measures to enable an assessment of the results of the project. The most important lesson for project design arising from the research relates to the need for sound monitoring and evaluation provisions to be built into project implementation. Economic variables of importance in this respect include the output of goods and services generated by enterprises located in the project site, household incomes and expenditures, trends in employment, tourist numbers and levels of spending and induced investments attributable to the project. It may also be possible to include the means to track some social and cultural impacts.

Another example is the analysis of the modernization projects of the Gallery of 19th-Century Polish Art in Krakow [16]. The main challenge of analyzing this case lies in the lack of critical data that was collected neither by the museums nor by other bodies, or experts. Therefore, analysis has to be based only on existing research, results of surveys and the data already collected by several institutions. Even institutions that benefited from the EU financial support for cohesion or development do not seem to be sufficiently aware of the importance of the potential impact their projects might have. Consequently, data to verify potential impact are usually not collected. Apart from the lack of awareness, the question of costs and shortage of financial resources hinders cultural institutions from running a monitoring of impact. Therefore, the analysis had to be done based on the scarce data and comparison of the successful projects found in the literature on the subject. The other problem faced here is the one of isolating the impact of the projects from their very complex settings. In case of the Gallery of 19th-Century Polish Art, located in the heart of Krakow's Old Town, it is rather difficult to say

\footnotetext{
${ }^{5}$ Europe is considered from a geographical and not an administrative perspective.
} 
whether the museum alone produces much impact - it is more likely the whole building of Sukiennice with its three parts, or even the whole complex of the Old Town, that in many cases could be analyzed as a whole.

As it is also assumed in Sect. 4, the brief comparative analysis of these three cases leads to an important lesson for conducting ex-post impact assessments: no matter where (the north, south, or east of Europe) or the specific approach (qualitative or quantitative), the primary constraint is likely to be the availability of data. The three research results deal with the need for comprehensive monitoring and evaluation tools to be integrated into the project implementation.

\section{Concluding Remarks}

There are many expectations placed on the ability of cultural heritage investments to have beneficial effects in terms of the generation of employment and income, especially for territories such as Calabria that combine an endowment of international appeal with still-low levels of enhancement.

The results highlighted by this first phase of the study raise questions both (1) on the topic of evaluation tools and methods to be used, and (2) on the topic of strategic planning and management of cultural heritage.

1.1 Availability of Data. On the former, it emerged that the choice of evaluation tools to be used for the assessment of the effectiveness of the public investment in the field of cultural built heritage is by no means simple. The methodology that can be applied in any economic analysis of a cultural heritage investment will be determined by the availability of data. In many cases, it has been proven that it is not feasible to carry out a fully articulated ex-post cost-benefit analysis along the lines described in the Thorsby case study. Nonetheless, a compilation of the types of indicators discussed by the author should be able to provide a useful picture of the project's effects, assuming that data relating to at least the most important effects can be captured.

1.2 Systemic Approach. In the literature and practice, many tools have been developed for the measurement of the impact of cultural projects. Given the likely significance of non-market benefits in the overall pattern of heritage project impacts, further steps should be taken in the development of methodologies adapted to the addressed field. A holistic approach should be chosen also for these methodologies and instruments to measure the spillover effects from cross-cutting issues regarding trans-categories, as well as trans-sectors benefits.

1.3 Heterogeneity and Comparability. A further issue concerns the heterogeneity and comparability of investments. The variability, in the case of the forts system, is linked at first instance to the financing/implementation timing. In the case of the Fort in Arghillà, there is a lack of availability of economic and financial data because the interventions were carried out in a European programming period (1994-1999) in which public expenditure monitoring was not yet foreseen. On the other hand, the other two interventions are too recent to have already produced visible effects. In fact, investments in cultural built heritage usually have a fairly long-time horizon. Furthermore, we can 
expect a distorting effect linked to the various characteristics of the territories affected by the investments, some concentrated in the suburban area of the capital city with more than 180,000 inhabitants (census 2017), the other in a municipality with less than 5,000 inhabitants (census 2017) ${ }^{6}$. The variability described makes the causal links to be sought unclear. The heterogeneity described make it particularly difficult to apply the counterfactual method, based on the comparison between actors/areas that have received or not received comparable treatments, both in terms of intervention type and intensity.

2.1 Regional Programs and the Evaluation Culture. Investments in culture and tourism infrastructure are therefore an excellent opportunity to test this relationship. There is a total of about 55 infrastructure projects, financed in the 2014-2020 programming period, for interventions ranging from urban regeneration to architectural restoration, from the enhancement of archaeological areas to the improvement of nature trails. In financial terms, it deals with more than 53 million euros of public investments, of which 35 million were made in the Metropolitan City of Reggio Calabria. It highlights the need for: an economic evaluation approach to support local policy makers in defining systemic territorial strategies that enable evaluating ex ante and in itinere, during the planning phase; where to allocate resources more effectively; and to appraise ex post the cultural heritage investment effects on the territory.

2.2 Local Strategic Planning and Management. As highlighted by this preliminary study on the Umbertine Forts System, the process of adding value to the assets has lacked strategic planning for the enhancement of this cultural built heritage. The critical issues that emerged are diverse: first of all, the idea of working on single elements without considering the value of the system as a whole. The peculiarity of this cultural built heritage stands in its essence of being a serial asset but configured as a unitary whole, even if articulated and complex, both from a geographical/landscape point of view and from an architectural/built one. Despite this being the year 2020, the refunctionalization of cultural built heritage still enshrines the restoration of cultural heritage as the main core of intervention, with little or no attention to management and functional objectives. The logic followed in these interventions is based on the idea that it is sufficient to restore and recover the physical structures of an asset so that all the conditions for an effective and positive impact on the local development of the territory are realized almost automatically: tourist and economic effects; enhancement of local productions; growth of the sense of belonging by young people; reversal of the exodus of the active population, creation of jobs, etc. The ineluctable result deals with a public funding of more than 10 million euros for the restoration of three forts of the Calabrianside of the system, and two out of three forts are not yet in operation.

2.3 Research Implementation. As repeatedly pointed out, more research is needed to acquire a more comprehensive and detailed understanding of the heritage spillovers in the economic, social, cultural and environmental domains, especially in light of the lack of available data. Therefore, the research implementation will address the design of a social cost-benefit analysis towards the identification of the economic, social, cultural and environmental impacts (positive and negative) generated by the

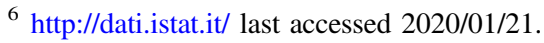


investments in the forts system valorization. The study's aim is to create useful technical support for operators who are preparing to plan and evaluate interventions for the redevelopment of cultural heritage.

The open questions raised by the preliminary step of the study presented here emphasize how the culture of evaluation is an essential step for achieving the overriding key objectives of efficiency, transparency, and accountability, with the aim of determining both the costs and the benefits of publicly financed projects, and to improve the efficiency and effectiveness of that investment. If well-resourced monitoring mechanisms could be routinely included when heritage projects are being implemented, the tracking of post-project performance in economic, social, and cultural terms would be greatly facilitated, and the quantity and quality of data available for expost impact analysis would accordingly be increased.

\section{References}

1. Porter, M.E., Kramer, M.R.: Creating shared value. Harv. Bus. Rev. 1(2), 2-17 (2011)

2. EC: European agenda for culture in a globalising world (2009). http://eur-lex.europa.eu

3. KEA: The Economy of Culture in Europe, Document prepared for the European Commission, Bruxelles (2006)

4. Della Spina, L.: A multi-level integrated approach to designing complex urban scenarios in support of strategic planning and urban regeneration. In: Calabrò, F., Della Spina, L., Bevilacqua, C. (eds.) ISHT 2018. SIST, vol. 100, pp. 226-237. Springer, Cham (2019). https://doi.org/10.1007/978-3-319-92099-3_27

5. Nesticò, A., Maselli, G.: Sustainability indicators for the economic evaluation of tourism investments on islands. J. Clean. Prod. 248, 119217 (2020). https://doi.org/10.1016/j.jclepro. 2019.119217

6. Cassalia, G., Tramontana, C., Calabrò, F.: Evaluation approach to the integrated valorization of territorial resources: the case study of the Tyrrhenian area of the metropolitan city of Reggio Calabria. In: Calabrò, F., Della Spina, L., Bevilacqua, C. (eds.) ISHT 2018. SIST, vol. 101, pp. 3-12. Springer, Cham (2019). https://doi.org/10.1007/978-3-319-92102-0_1

7. UVAL: L'Italia secondo i Conti Pubblici Territoriali. I flussi finanziari pubblici nel settore cultura e servizi ricreativi. Atti del convegno di presentazione, Collana Materiali UVAL n.3, (2014)

8. Barca, F.: Towards a place-based social agenda for the EU. Report Working Paper (2009)

9. Mollica, E.: Le Aree Interne della Calabria. Rubbettino, Soveria Mannelli (1997)

10. Calabrò, F., Della Spina, L.: The public-private partnership for the enhancement of unused public buildings: an experimental model of economic feasibility project. Sustainability 11, 5662 (2019). https://doi.org/10.3390/su11205662

11. Banchini, R., Meduri, T., Tramontana, C.: La valorizzazione delle risorse architettoniche per la costruzione della Città Metropolitana dello Stretto: il recupero dei Forti di Pentimele. LaborEst 5, 29-31 (2010)

12. UVAL: Approcci alla valutazione degli effetti delle politiche di sviluppo regionale, Collana Materiali UVAL n. 22 (2011)

13. Lichfield, N.: Economics in Urban Conservation. Cambridge University Press, Cambridge (1988)

14. Pearce, D.W., Mourato, S.: The Economics of Cultural Heritage. World Bank Report, CSERGE, University College London (1998) 
15. Ost, C., Van Droogenbroeck, N.: A Report on Economics of Conservation. ICOMOS, Brussels (1998)

16. CHCFE Consortium: Cultural Heritage counts for Europe (2015). http://www.europanostra. org/our-work/policy/cultural-heritage-counts-europe/. Accessed 21 Jan 2020

17. Throsby, D.: Investment in urban heritage: economic impacts of cultural heritage projects in FYR Macedonia and Georgia. Urban development series (16). World Bank, Washington DC (2012)

18. Carson, R.T., Mitchell, R.C., Conaway, M.B.: Economic benefits to foreigners visiting Morocco accruing from the rehabilitation of the Fes Medina. In: Navrud, S., Ready, R.C. (eds.) Valuing Cultural Heritage: Applying Environmental Valuation Techniques to Historic Buildings, Monuments and Artifacts, pp. 118-141. Edward Elgar, Cheltenham (2002)

19. Kinghorn, N., Willis, K.: Valuing the components of an archaeological site: an application of choice experiment to Vindolanda, Hadrian's Wall. J. Cult. Herit. 9(2), 117-124 (2008)

20. Plaza, B.: The return on investment of the Guggenheim Museum Bilbao. Int. J. Urban Reg. Res. 30(2), 452-467 (2006)

21. Noonan, D.S.: Finding an impact of preservation policies: price effects of historic landmarks on attached homes in Chicago, 1990-1999. Econ. Develop. Q. 21(1), 17-33 (2007)

22. Nicolosi, A., Laganà, V.R., Cortese, L., Privitera, D.: Using the network and MCA on tourist attractions. The case of Aeolian Islands, Italy. Sustainability 10, 4169 (2018)

23. Poor, P.J., Smith, J.M.: Travel cost analysis of a cultural heritage site: the case of historic St. Mary's City of Maryland. J. Cult. Econ. 28(3), 217-229 (2004)

24. Navrud, S., Strand, J.: Social costs and benefits of preserving and restoring the Nidaros Cathedral. In: Navrud, S., Ready, R.C. (eds.) Valuing Cultural Heritage: Applying Environmental Valuation Techniques to Historic Buildings, Monuments and Artifacts, pp. 118-141. Edward Elgar, Cheltenham (2002)

25. Locurcio, M., Tajani, F., Morano, P., Torre, C.M.: A fuzzy multi-criteria decision model for the regeneration of the urban peripheries. New Metrop. Perspect. 100, 681-690 (2019). https://doi.org/10.1007/978-3-319-92099-3_76

26. Sturiale, L., Scuderi, A., Timpanaro, G., Foti, V.T., Stella, G.: Social and inclusive "value" generation in metropolitan area with the "urban gardens" planning. In: Mondini, G., Oppio, A., Stanghellini, S., Bottero, M., Abastante, F. (eds.) Values and Functions for Future Cities. GET, pp. 285-302. Springer, Cham (2020). https://doi.org/10.1007/978-3-030-23786-8_16

27. Saganeiti, L., Favale, A., Pilogallo, A., Scorza, F., Murgante, B.: Assessing urban fragmentation at regional scale using sprinkling indexes. Sustainability 10, 3274 (2018). https://doi.org/10.3390/su10093274

Open Access This chapter is licensed under the terms of the Creative Commons Attribution 4.0 International License (http://creativecommons.org/licenses/by/4.0/), which permits use, sharing, adaptation, distribution and reproduction in any medium or format, as long as you give appropriate credit to the original author(s) and the source, provide a link to the Creative Commons license and indicate if changes were made.

The images or other third party material in this chapter are included in the chapter's Creative Commons license, unless indicated otherwise in a credit line to the material. If material is not included in the chapter's Creative Commons license and your intended use is not permitted by statutory regulation or exceeds the permitted use, you will need to obtain permission directly from the copyright holder.

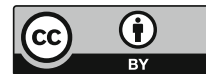

